\title{
Role of Integrin-Linked Kinase in Nerve Growth Factor-Stimulated Neurite Outgrowth
}

\author{
Julia Mills, ${ }^{1}$ Murat Digicaylioglu, ${ }^{5}$ Arthur T. Legg, ${ }^{2}$ Clint E. Young, ${ }^{4}$ Sean S. Young, ${ }^{1}$ Alasdair M. Barr, ${ }^{3}$ Lauren Fletcher, ${ }^{5}$ \\ Timothy P. O'Connor, ${ }^{2}$ and Shoukat Dedhar ${ }^{1}$ \\ 'Department of Biochemistry and Molecular Biology, University of British Columbia, Vancouver, Canada V6T 123, and British Columbia Cancer Agency, \\ British Columbia, Canada V6H 326, ${ }^{2}$ Department of Anatomy and Cell Biology, University of British Columbia, Vancouver, British Columbia, Canada \\ V6T 123, ${ }^{3}$ Department of Psychology, University of British Columbia, Vancouver, British Columbia, Canada V6T 124, ${ }^{4}$ Department of Psychiatry, University \\ of British Columbia, Vancouver, British Columbia, Canada V6T 2A1, and ${ }^{5} \mathrm{Center}$ for Neuroscience and Aging Research, The Burnham Institute, La Jolla, \\ California 92037
}

\begin{abstract}
The role of integrin-linked kinase (ILK), a kinase that is involved in various cellular processes, including adhesion and migration, has not been studied in primary neurons. Using mRNA dot blot and Western blot analysis of ILK in rat and human brain tissue, we found that ILK is expressed in various regions of the CNS. Immunohistochemical and immunocytochemical techniques revealed granular ILK staining that is enriched in neurons and colocalizes with the $\beta 1$ integrin subunit. The role of ILK in neurite growth promotion by NGF was studied in rat pheochromocytoma cells and dorsal root ganglion neurons using a pharmacological inhibitor of ILK (KP-392) or after overexpression of dominant-negative ILK (ILK-DN). Both molecular and pharmacological inhibition of ILK activity significantly reduced NGFinduced neurite outgrowth. Survival assays indicate that KP-392-induced suppression of neurite outgrowth occurred in the absence of cell death. ILK kinase activity was stimulated by NGF. NGF-mediated stimulation of phosphorylation of both AKT and the Tau kinase glycogen synthase kinase-3 (GSK-3) was inhibited in the presence of KP-392 and after overexpression of ILK-DN. Consequently, ILK inhibition resulted in an increase in the hyperphosphorylation of Tau, a substrate of GSK-3. Together these findings indicate that ILK is an important effector in NGF-mediated neurite outgrowth.
\end{abstract}

Key words: integrin-linked kinase; glycogen synthase kinase-3; NGF; neurite growth; AKT; $\beta 1$ integrin; extracellular matrix

\section{Introduction}

Integrin linked-kinase (ILK) is a $59 \mathrm{kDa}$, phosphatidylinositol-3 kinase (PI-3 kinase)-dependent, serine-threonine kinase that regulates various cellular processes, including adhesion, migration, differentiation, and survival (for review, see Dedhar et al., 1999; Wu, 1999; Dedhar, 2000; Wu and Dedhar, 2001). ILK contains four ankyrin repeats at the $\mathrm{NH}_{2}$ terminus followed by a pleckstrin homology (PH)-like domain and a protein kinase catalytic domain near the $\mathrm{COOH}$ terminus (Hannigan et al., 1996). ILK interacts with $\beta 1$ and $\beta 3$ integrins through its $C$ terminus (Hannigan et al., 1996), the LIM domain-only adaptor protein particularly interesting new cysteine-histidine rich protein (PINCH) through its ankyrin repeat domains (Tu et al., 1999) and may interact with phosphatidylinositol phosphates through the PH domain motif (Delcommenne et al., 1998). The ILKPINCH interaction is important for its localization within focal adhesions (Li et al., 1999) and is thought to link ILK with growth factor receptor kinase signaling by way of other PINCH binding proteins such as Nck-2 (Tu et al., 1998). PINCH and Nck-2 form a ternary complex with ILK and are recruited to activated growth factor receptors (Tu et al., 1999). ILK also binds paxillin and the

Received April 29, 2002; revised Dec. 3, 2002; accepted Dec. 6, 2002.

This work was supported by research grants to S.D. from the National Cancer Institute of Canada and Canadian Institutes of Health Research (CIHR) and by research grants to M.D. from the National Institutes of Health. J.M. is supported by a fellowship from the CIHR.

Correspondence should be addressed to Shoukat Dedhar, Jack Bell Research Centre, 2660 0ak Street, Vancouver, British Columbia, Canada V6H 3Z6. E-mail: sdedhar@interchange.ubc.ca.

Copyright $\odot 2003$ Society for Neuroscience $\quad$ 0270-6474/03/231638-11\$15.00/0 calponin homology containing actin binding proteins affixin (Yamaji et al., 2001) and calponin homology ILK-binding protein (CH-ILKBP) (Tu et al., 2001) within focal adhesions (Nikolopoulos and Turner, 2001). These protein-protein interactions provide a framework for the formation of ILK signaling complexes that couple integrins and growth factors to the cytoskeleton (Wu and Dedhar, 2001).

ILK has been shown to be a critical effector in a PI-3 kinasedependent signaling pathway that is downstream from both growth factor and integrin receptor activation (for reviews see Dedhar et al., 1999; Wu, 1999). Stimulation of ILK after exposure to soluble factors or fibronectin results in activation of AKT (also known as protein kinase B) and inhibition of glycogen synthase kinase-3 (GSK-3) (Delcommenne et al., 1998; Attwell et al., 2000; Dedhar, 2000; Persad et al., 2000). Phosphoinhibition of GSK-3 by ILK may be direct because ILK has been shown to phosphorylate GSK-3 in vitro (Delcommenne et al., 1998; Persad et al., 2001b). Alternatively, activated AKT may, in turn, phosphorylate and thereby negatively regulate GSK-3 (Cross et al., 1995).

The PI-3 kinase-dependent-AKT signaling pathway has been shown to be involved in neuronal differentiation and is downstream of both integrins (Sarner et al., 2000) and growth factors such as NGF (Kaplan and Miller, 2000). ILK is a known effector within the AKT signaling pathway and has recently been shown to regulate migration and differentiation (Ishii et al., 2001; Wu and Dedhar, 2001). Therefore, we examined the role of ILK in NGF-induced activation of AKT and neurite outgrowth using pheochromocytoma cells (PC12) cells, dorsal root ganglion 


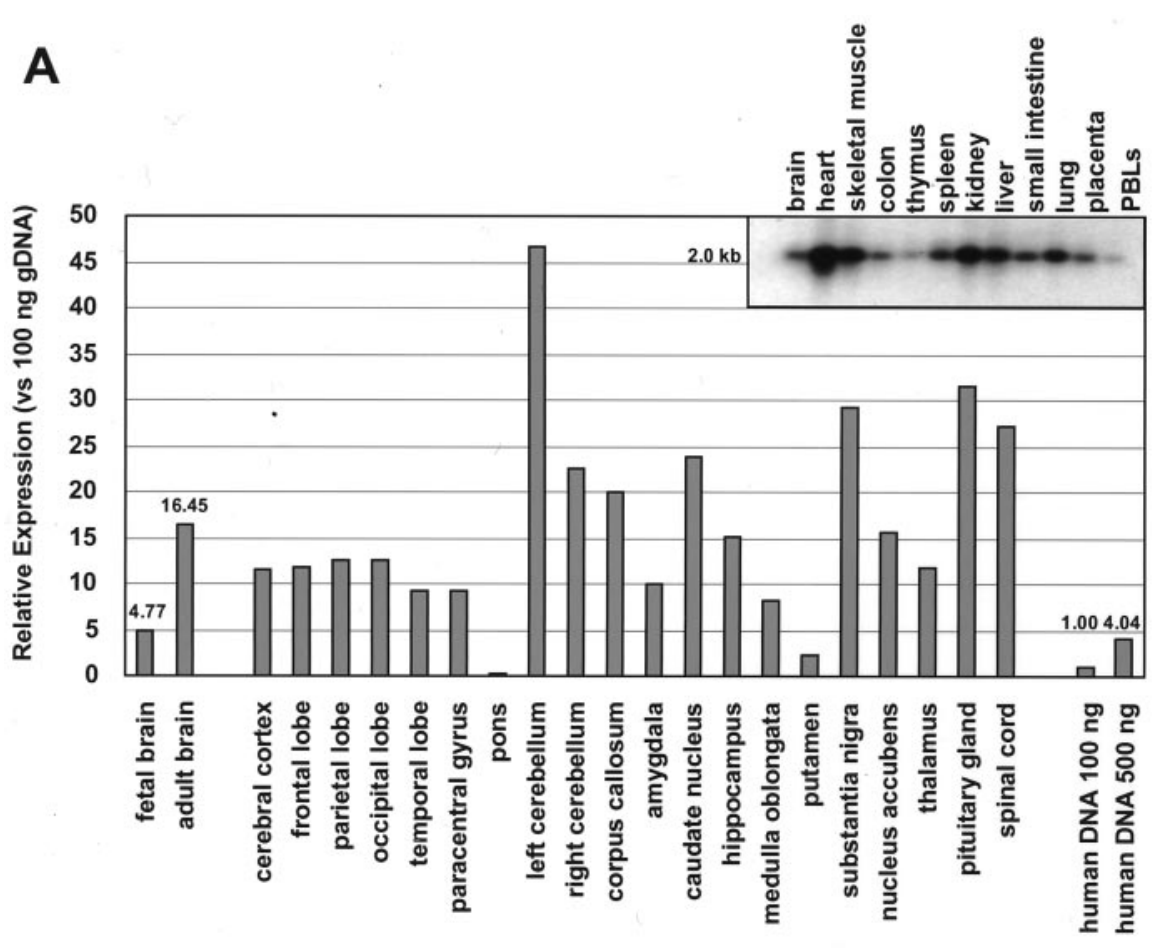

B

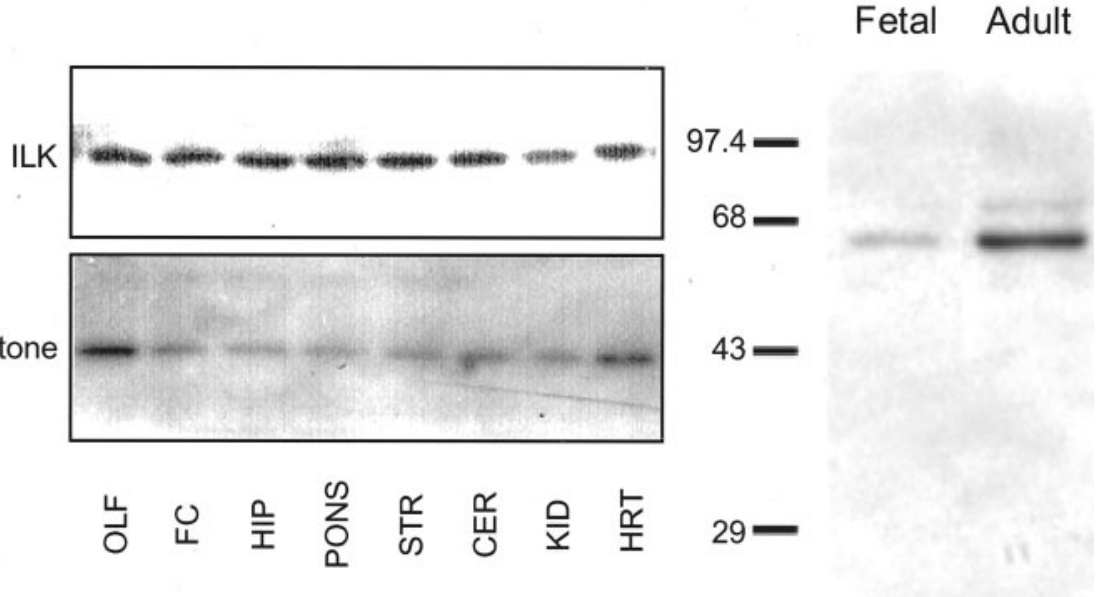

Figure 1. ILK transcript and protein expression in rat and human tissue. $A$, Human multiple tissue expression array. The signals obtained by hybridization of an ILK-specific probe to the multiple tissue expression membrane were quantified by phosphoimage analysis, as described in Materials and Methods. The data are represented as fold increases over the signal obtained from $100 \mathrm{ng}$ of genomic DNA. Inset, Specificity of the ILK probe was assured by Northern blot analysis. B, Top, Rat homogenates from neural (olfactory bulb, lane 1; frontal cortex, lane 2; hippocampus, lane 3; pons, lane 4; striatum, lane 5; cerebellum, lane 6) and nonneuronal (kidney, lane 7; heart, lane 8) tissues were immunoblotted and probed with an ILK polyclonal antibody from Upstate Biotechnology. Bottom, Western blots were also probed with a histone $\mathrm{H} 1$ monoclonal antibody as a loading control. C, Representative Western blot, performed in triplicate, showing ILK expression in adult or fetal (7 week) human brain tissue. ILK was visualized using a rabbit polyclonal antibody (Upstate Biotechnology).

(DRG) neurons, and cerebrocortical neurons. We find that ILK is activated by NGF and is an important effector of NGF-mediated neurite outgrowth.

\section{Materials and Methods}

Cell culture and drug exposure. PC12 cells were grown in DMEM supplemented with 5\% FBS, 10\% horse serum, and 1\% nonessential amino acids. PC12 cells overexpressing gp $140^{\text {trk }}$ (cell line PC-6-24) were grown in the same medium except that newborn calf serum was used instead of FBS, and cells were maintained in the presence of $200 \mu \mathrm{g} / \mathrm{ml} \mathrm{G418}$ as previously described (Hempstead et al., 1992). Before drug exposure,
PC12 cells were plated onto collagen I $(5 \mu \mathrm{g} / \mathrm{ml}$; Collaborative Biomedical Products, Bedford, MA), collagen IV $(2 \mu \mathrm{g} / \mathrm{ml}$; Invitrogen, Burlington, Ontario, Canada), or laminin ( $5 \mu \mathrm{g} / \mathrm{ml}$; Invitrogen) at a density of $3 \times 10^{6} / 100 \mathrm{~mm}$ dish for Western blotting, $8.7 \times 10^{6} / 100 \mathrm{~mm}$ dish for kinase assays or $5 \times 10^{5} / 35 \mathrm{~mm}$ dish for neurite outgrowth assays and allowed to adhere overnight. Cells were then exposed to NGF (Invitrogen) in serum-free DMEM with or without $100 \mu \mathrm{M}$ of the selective ILK inhibitor KP-392 (formerly known as KP-SD-1; Persad et al., 2000, 2001a,b, Troussard et al., 2000; Tan et al., 2001). Short-term exposures ( $4 \mathrm{hr}$ ) of PC12 cells to the ILK inhibitor were preceded by a $1 \mathrm{hr}$ preincubation. KP-392 was obtained from a local pharmaceutical company (Kinetek Pharmaceuticals Inc., Vancouver, British Columbia, Canada) after a material transfer agreement. For transfection experiments, E359K dominant-negative ILK (ILK-DN), wild-type ILK (ILK-WT), or empty vector (Delcommenne et al., 1998) were transiently expressed in PC12 cells using Lipofectamine 2000 (Invitrogen) 24 $\mathrm{hr}$ before cell plating. Cultures were subsequently plated onto collagen I, serum-starved overnight, and exposed to NGF. In experiments measuring neurite outgrowth, enhanced green fluorescent protein (EGFP) was transiently cotransfected with either ILK constructs or empty vector, and measurements were taken from EGFP-positive cells. PC-6-24 cells were plated onto collagen I-coated glass coverslips and allowed to differentiate for $2 \mathrm{~d}$ in the presence of $50 \mathrm{ng} / \mathrm{ml} \mathrm{NGF}$. Cultures of cerebellar granule cells were prepared from the cerebella of postnatal day 4-5 mice as previously described (Cohen-Cory et al., 1991). Cells were plated on laminin-coated glass coverslips in MEM containing $10 \% \mathrm{FCS}$ and $25 \mathrm{~mm} \mathrm{KCl}$ and allowed to adhere overnight. Cerebellar cultures were then incubated in Neurobasal media (Invitrogen) supplemented with B-27 (Invitrogen) and allowed to differentiate for 7-8 d in vitro. DRG cells were isolated from stage 29-30 (E6-E6.5; 25) chick embryos (White Leghorn, Alberta) at lumbosacral levels. The DRG neurons were cultured on coverslips coated with poly-L-lysine (100 $\mu \mathrm{g} / \mathrm{ml})$ and laminin $(50 \mu \mathrm{g} / \mathrm{ml})$ in DMEM-F-12 media containing $1 \% \mathrm{FBS}, 20 \mathrm{ng} / \mathrm{ml} \mathrm{NGF}$, and 5 $\mu \mathrm{g} / \mathrm{ml}$ insulin. One hundred micromolar KP-392 (Kinetek Pharmaceuticals Inc.) alone or with 100 $\mu \mathrm{M}$ Boc-aspartyl (OMe)-fluoromethylketone (BAF; Enzyme Systems Products, Dublin, CA) was added to the explants before plating. DMSO (equal volumes) was added to control cultures. Cells were subsequently cultured for $24 \mathrm{hr}$ in the presence of drug or vehicle control. Cerebrocortical cultures were prepared from embryonic day 15 or 16 Sprague Dawley rats as previously described (Bonfoco et al., 1995) and plated onto poly-D-lysinecoated culture plates. Cerebrocortical cultures were transiently transfected with ILK-DN or ILK-WT using Lipofectamine 2000 (Invitrogen). Cultures were serum-starved $16 \mathrm{hr}$ before drug addition and exposed to NGF (20 $\mathrm{ng} / \mathrm{ml}$ ) (Calbiochem, La Jolla, CA) for 15 min in Earle's balanced salt solution and subsequently harvested for kinase assays.

Terminal deoxynucleotidyl transferase-mediated biotinylated UTP nick end labeling and propidium iodide staining. For terminal deoxynucleotidyl transferase-mediated biotinylated UTP nick end labeling (TUNEL) labeling, PC12 cells were plated onto coverslips coated with poly-D-lysine 


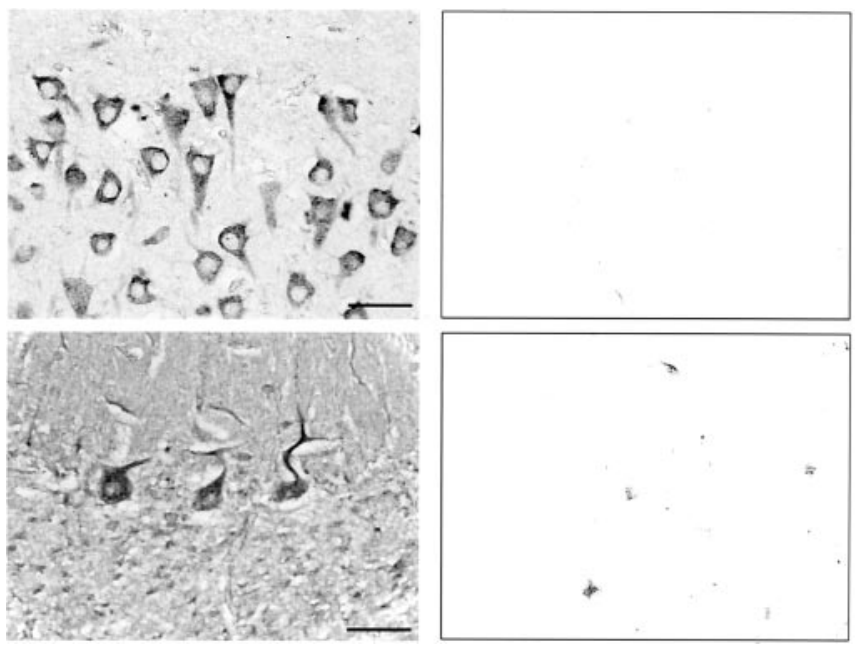

Figure 2. Immunohistochemical staining of ILK is enhanced in neurons from the human hippocampus and cerebellum. Coronal sections through the hippocampus (top left panel) or cerebellum (bottom left panel) showing high somatodendritic ILK immunoreactivity in both CA1 pyramidal cells and Purkinje cells, respectively. IgG controls for both sections are shown in the adjacent panels. Scale bar, $50 \mu \mathrm{m}$.

$(100 \mu \mathrm{g} / \mathrm{ml})$ and collagen I. After a $48 \mathrm{hr}$ drug treatment, DNA fragmentation was measured in PC12 cells using the In Situ Cell Death Detection Kit (Fluorescein; Boehringer Mannheim Biochemicals, Indianapolis, IN) according to the methods of Miller et al. (1997). Cells were then washed in PBS and mounted in Vectashield mounting media containing DAPI (Vector Laboratories, Burlingame, CA). For propidium iodide staining, PC12 cells were incubated in DMEM containing propidium iodide (100 $\mu \mathrm{g} / \mathrm{ml})$ and Hoechst $33342(50 \mu \mathrm{g} / \mathrm{ml})$ for $15 \mathrm{~min}$ at room temperature, washed with PBS, and fixed with $3 \%$ paraformaldehyde. The number of TUNEL-negative or propidium iodide-negative cells were calculated as a percentage of total cell number (DAPI or Hoechst-stained cells, respectively).

Assessment of neurite growth. The number of neurite-bearing PC12 cells was assessed as previously described (Teng and Greene, 1994). In brief, cells with neurites were defined as those bearing a process greater than twice the cell body length. The percentage of cells with neurites for each treatment group was determined using randomly chosen cell fields from duplicate wells. For transfected cultures, measurements were taken from PC12 cells expressing EGFP. Data were expressed as mean \pm SEM of four separate trials. ${ }^{\star} p<0.05$ different from control cells plated onto the same extracellular matrix. In DRG explants, the average length of neurite bundles was measured from the outer edge of the explant to the outer perimeter of the bulk of neurofilament-stained neurites. In addition, individual neurite bundles were counted as they crossed each concentric circle located at 500, 1000, and $1500 \mu \mathrm{m}$ from the edge of the explant. Ten DRG explants (taken from four separate platings) were scored for both the control (DMSO) and experimental groups (KP-392). In both PC12 cells and DRG neurons, paired $t$ tests were used to determine the significance of observed differences.

Kinase assay and immunoprecipitations. Primary neuronal cultures were washed in PBS and harvested in ice-cold lysis buffer $(50 \mathrm{~mm}$ Tris$\mathrm{HCl}, \mathrm{pH} 8.0,150 \mathrm{~mm} \mathrm{NaCl}, 1 \%$ Triton X-100, 0.1\% deoxycholate, $1.1 \mathrm{~mm}$ PMSF, $10 \mu \mathrm{g} / \mathrm{ml}$ aprotinin, $2 \mathrm{~mm}$ orthovanadate, and $100 \mathrm{~mm} \mathrm{NaF}$ ). Lysates were precleared by centrifugation $(20 \mathrm{~min}$ at $14,000 \times \mathrm{g}$ ), and protein concentrations were determined using a BCA protein assay kit (Pierce, Rockford, IL). Lysates were subsequently immunoprecipitated with a monoclonal antibody (Upstate Biotechnology, Lake Placid, NY) to ILK, and the protein kinase assay was performed as previously described (Digicaylioglu and Lipton, 2001) using an $\mathrm{N}$ terminus, His-tagged fusion protein corresponding to human AKT as a substrate (Upstate Biotechnology). After the kinase assay, anti-ILK immune complexes were subjected to Western blot analysis to measure phosphorylation of exogenous AKT at Ser-473. ILK kinase activity was measured in PC12 cells after
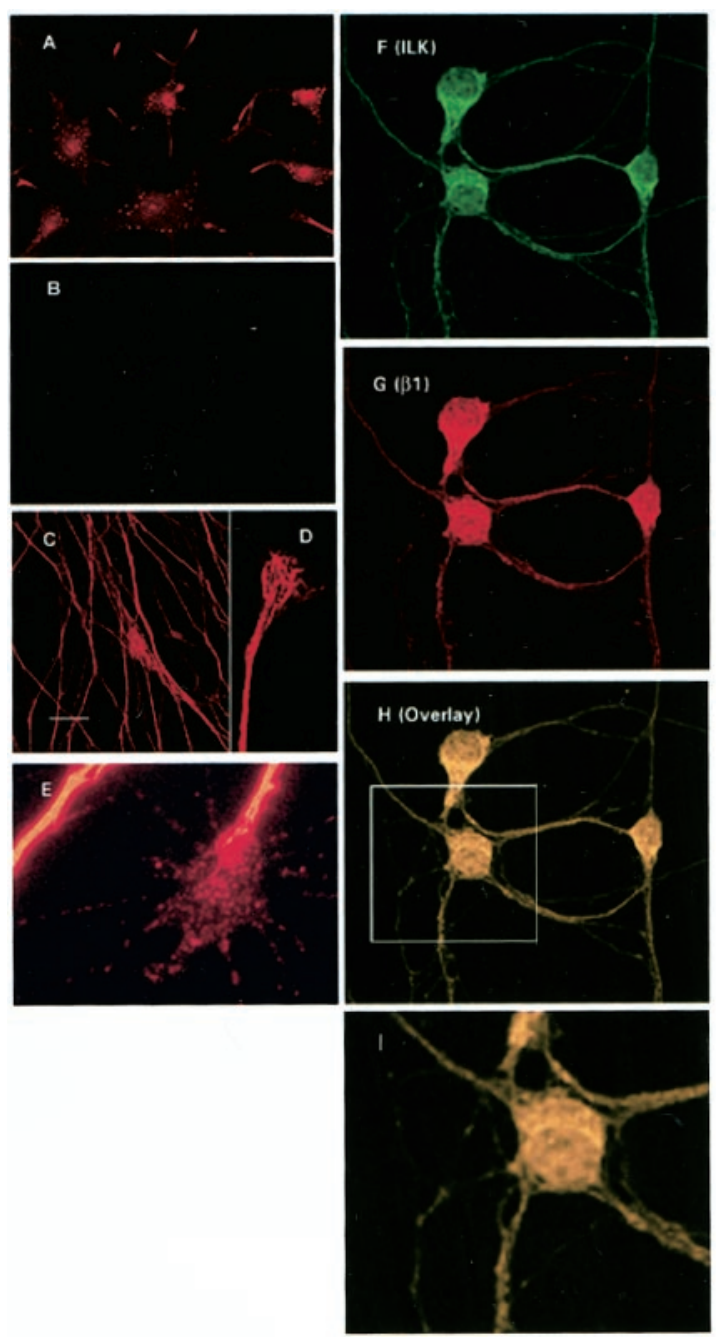

Figure 3. Immunocytochemical localization of ILK and $\beta 1$ integrin in neuronal cells. Labeling of cells with ILK reveal both a punctate and continuous staining pattern with concentrations at the axon, neurite tip, and periphery of the cell soma. $A$, Punctate immunoreactivity was evident in differentiated PC12 cells overexpressing gp $140^{\text {trk }}$ and plated onto collagen I after incubation with a polyclonal ILK antibody $(A)$ but was not present in the corresponding IgG controls $(B)$. Immunoreactivity to an anti-ILK antibody was continuous at the axons of DRG neurons plated onto laminin $(C, D)$ but appeared more patchy and granular at the growth cone (E). Codistribution of ILK and the $\beta 1$ integrin subunit occurred throughout the neuronal cell body and processes of cerebellar granule neurons $(F-H)$. Area outlined by the box $(H)$ is shown here at a higher magnification (I). Scale bar, $20 \mu \mathrm{m}$.

immunoprecipitation with a monoclonal anti-ILK antibody (Upstate Biotechnology) as described above or by ${ }^{32} \mathrm{P}$ phosphorylation of exogenous AKT. The latter ILK immunoprecipitation kinase assay is a modification of one used for phosphoinositide-dependent kinase-1 (PDK) activity (Upstate Biotechnology). Levels of the p85 regulatory subunit of PI-3 kinase in anti-phosphotyrosine immunoprecipitates of PC12 cells were analyzed as a control for KP-392. A specific antibody against phosphotyrosine (PY20; Santa Cruz Biotechnology, Santa Cruz, CA) was used for immunoprecipitations.

Western blotting. Rodent tissue, harvested from 6- to 8-week-old rats (250-275 gm adult male Sprague Dawley), and PC12 cell homogenates were prepared in Tris-HCl buffer, pH 7.6, containing 1\% NP-40, $150 \mathrm{~mm}$ $\mathrm{NaCl}, 1 \mathrm{~mm}$ EDTA, $3.8 \mu \mathrm{g} / \mathrm{ml}$ aprotinin, $1 \mu \mathrm{g} / \mathrm{ml}$ leupeptin, $1 \mathrm{~mm}$ PMSF, $2 \mathrm{~mm} \mathrm{NaF}$, and $1 \mathrm{~mm} \mathrm{Na}_{3} \mathrm{VO}_{4}$. NP-40 buffer has previously been shown to be suitable for the recovery of other focal adhesion proteins (Ling et al., 1999). For Trk (tyrosine kinase) Western blots, lysis buffer was supplemented with $0.1 \%$ SDS. After sonication, $20 \mu \mathrm{g}$ of protein was separated by $10 \%$ SDS-PAGE and transferred electrophoretically to polyvinylidene 
A

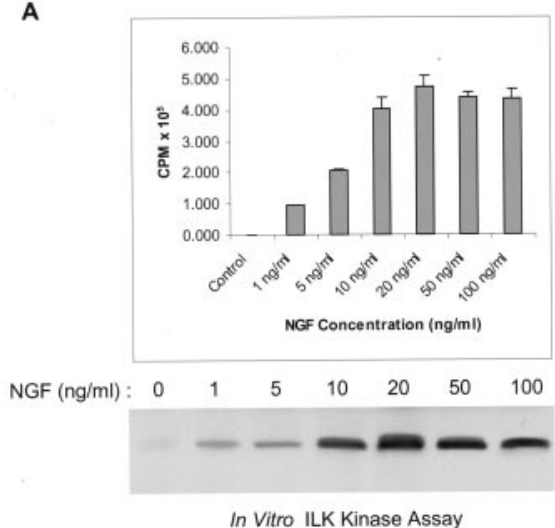

B

C

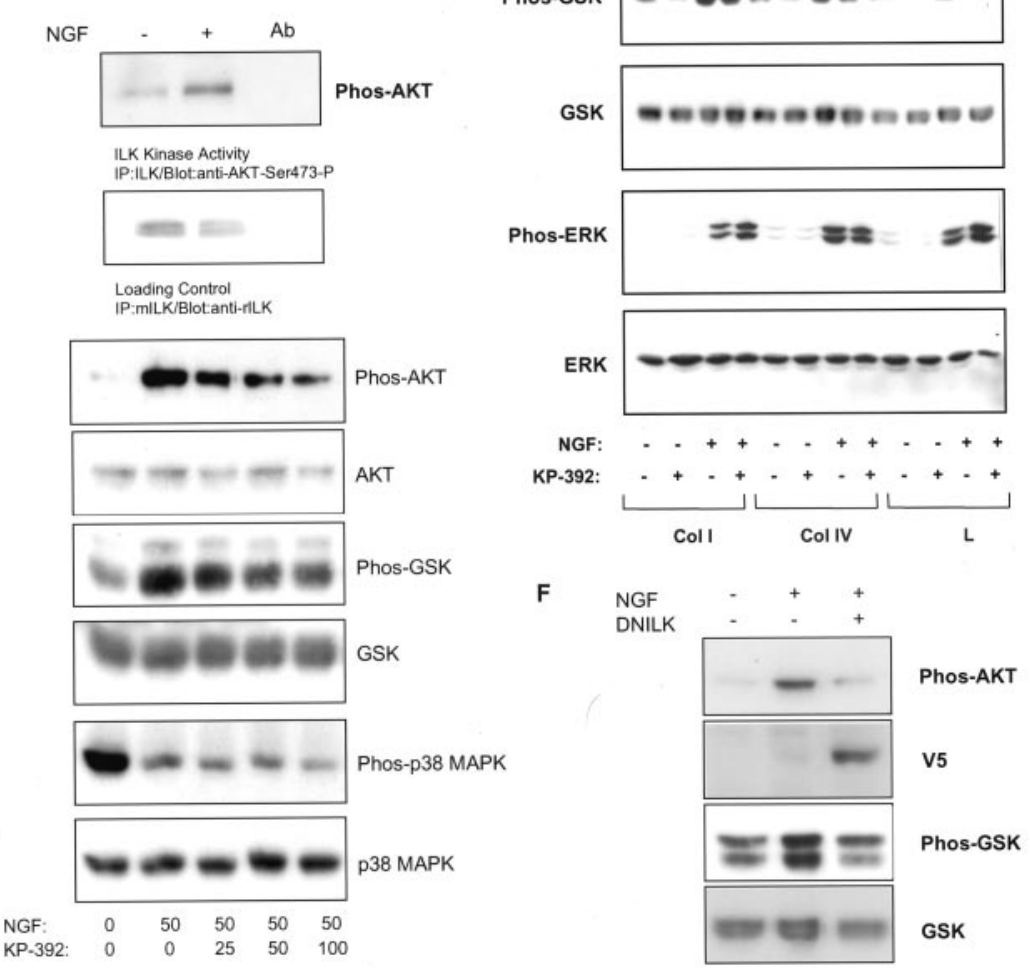

Figure 4. ILK inhibition reduces AKT and GSK-3 phosphorylation in $\mathrm{PC1} 2$ cells after NGF receptor stimulation. A, NGF increases ILK activity in a concentration-dependent manner. PC12 cells, plated onto laminin, were exposed to increasing concentrations of NGF for $30 \mathrm{~min}$. After immunoprecipitation, ILK activity was measured by AKT substrate radiolabeling. Top, Average CPM of AKT substrate radiolabeling; $n=3 \pm$ SEM. Bottom, Representative in vitro kinase assay. B, NGF increases ILK phosphorylation of AKT Ser-473. ILK kinase activity was measured in PC12 cells plated onto collagen I after a 10 min exposure to NGF (100 ng/ml). ILK activity was measured using a His-tagged fusion protein corresponding to human AKT as an exogenous substrate. Phosphorylation of the substrate by ILK is detected using a phosphospecific anti-AKT Ser-473 antibody. The antibody control (lane 3) corresponds to lysate immunoprecipitated with an irrelevant antibody (anti-flag monoclonal antibody; Upstate Biotechnology). C, KP-392 inhibits NGF stimulation of AKT and GSK phosphorylation in a dose-dependent manner. Western blots of lysates from PC12 cells grown on collagen I and treated with NGF $(50 \mathrm{ng} / \mathrm{ml})$ for $4 \mathrm{hr}$ in the presence of vehicle control or increasing concentrations of KP-392. Representative Western blots of cell lysates, run in parallel and probed with antibodies for phospho-AKT, phosphoGSK-3, or phospho-p38 MAPK; $n=3-5$. These same blots were subsequently stripped and reprobed for AKT, GSK-3, or P38 MAPK as a control for protein expression levels. D, KP-392 does not inhibit phosphorylation of PI-3 kinase or TrkA. Left, Representative Western blot of PC12 cell lysates from PC12 cells treated for $4 \mathrm{hr}$ with NGF in the presence or absence of KP-392 (100 $\mu \mathrm{M})$ and probed with a phosphospecific antibody for $\operatorname{TrkA}\left(\mathrm{Tyr}^{490}\right)$. Right, Levels of the $\mathrm{p} 85$ regulatory subunit of $\mathrm{PI}-3$ kinase were analyzed in anti-phosphotyrosine immunoprecipitates by Western blotting. $E$, Long-term effects of KP-392 (100 $\mu \mathrm{M})$ on cell signaling in PC12 cells grown on collagen I (Col I), collagen IV ( $\mathrm{Cl} / \mathrm{IV})$, or laminin $(L)$ and incubated in the presence or absence of NGF $(50 \mathrm{ng} / \mathrm{ml})$ for $48 \mathrm{hr}$. Representative Western blots of cell lysates, run in parallel and probed with antibodies for phospho-AKT, phosphoGSK-3, or phospho-ERK; $n=3$. After membrane stripping, Western blots were subsequently reprobed for AKT, GSK-3, and ERK. $F$, Overexpression of ILK-DN decreases NGF-induced stimulation of AKT and GSK-3 phosphorylation. PC12 cells were transfected with ILK$\mathrm{DN}: \mathrm{V}_{5}$ or Empty $\mathrm{V}_{5}$. Twenty-four hours after transfection, cells were replated onto collagen I and were serum-starved overnight. Representative Western blots of phospho-AKT and phospho-GSK-3 after a 15 min exposure to NGF $(50 \mathrm{ng} / \mathrm{ml}) ; n=3$. These same Western blots were subsequently stripped and reprobed with an anti-V ${ }_{5}$ or anti-GSK-3 antibody, respectively. difluoride. Human tissue was solubilized in buffer containing $0.1 \%$ Triton X-100, and 15 $\mu \mathrm{g}$ of sample was separated by $15 \%$ SDS-PAGE. Membranes were probed with antibodies to the following: ILK (StressGen Biotechnologies Corporation, Victoria, British Columbia, Canada; Upstate Biotechnology), AKT (New England Biolabs, Mississauga, Ontario, Canada), phospho-AKT Ser-473 (New England Biolabs), GSK-3 (BD PharMingen, Mississauga, Ontario, Canada), phospho-GSK-3 $\alpha / \beta$ (Ser-21/9; New England Biolabs), p38 MAPK (mitogenactivated protein kinase) (New England Biolabs), phospho-p38 MAPK (New England Biolabs), tau-1 (Chemicon, Temecula, CA), paired helical filament (PHF-1; a kind gift from Dr. Davies, The Albert Einstein College of Medicine), Trk (C14; Santa Cruz Biotechnology), phosphospecific TrkA (Tyr ${ }^{490}$; New England Biolabs), and histones ( $\mathrm{H} 1$ and core proteins; Chemicon). For Western blots of extracellular signal-regulated kinase (ERK), protein was separated on $12.5 \%$ low bis gels (acrylamide:bis ratio 118.5:1), transferred and probed using a phospho-ERK antibody (New England Biolabs). Western blots of AKT, GSK-3, p38 MAPK, and TrkA were probed first with phosphospecific antibodies, stripped using Restore buffer (Pierce), and subsequently reprobed with nonphosphospecific antibodies as controls for total protein expression. Western blots of Tau were probed first with anti-PHF-1, a phosphorylation-dependent antibody that binds a phosphoserine residue (phosphoserine 396) which lies next to the microtubule binding domain of Tau and then with antiTau-1 a phosphorylation-independent antibody. All antibodies, were used at a dilution of 1:1000 except for the following: anti-PHF-1 (1:50), antiTau-1 (1:500), anti-phosphospecific TrkA (1: 500 ), and anti-histones (1:500).

Human multiple tissue expression array. A ${ }^{32} \mathrm{P}$-labeled cDNA probe corresponding to the $5^{\prime}$ end of ILK (ATG-BamHI) was generated by random prime labeling (Redi-prime II, Amersham Pharmacia Biotech, Baie d-Urfé, Quebec, Canada). The specificity of the probe was assured by standard Northern blot analysis (human 12-lane multiple tissue Northern blot; Clontech, Palo Alto, CA). The tissue distribution of ILK was measured by hybridization of the probe to a multiple tissue mRNA dot blot (human multiple tissue expression array; Clontech). All hybridizations and subsequent washing steps were performed according to the manufacturer's protocol. The resulting blot was then visualized by autoradiography. Expression was quantified with a Storm 860 PhosphorImager (Molecular Dynamics, Sunnyvale, CA) and the accompanying ImageQuant analysis software, version 4.1 (Molecular Dynamics). Data from individual spots were then corrected for background signal (Cot 1 DNA) and normalized against the signal obtained from $100 \mathrm{ng}$ of genomic DNA.

Immunocytochemistry. Human brain sections $(3-5 \mu \mathrm{M})$ cut from paraffin-embedded tissues were deparaffinized, permeabilized in $0.2 \%$ Triton X-100, and stained using a polyclonal antibody against ILK (1:250; Upstate 


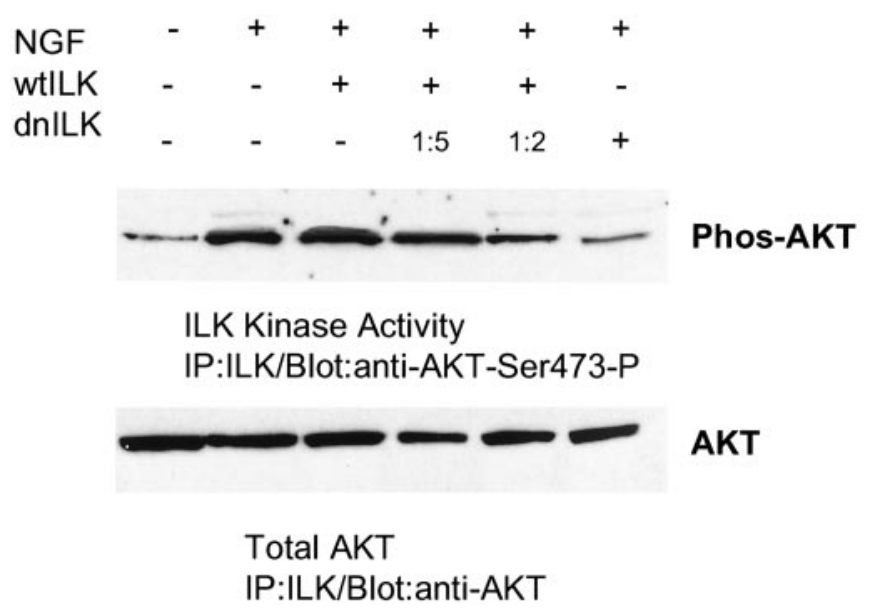

Figure 5. NGF increases phosphorylation of AKT Ser-473: effect of ILK-DN and ILK-WT overexpression in primary neurons. Top, ILK in vitro kinase activity was measured in rat cerebrocortical cultures after a 15 min exposure to NGF. NGF increased ILK phosphorylation of AKT Ser-473. Growth factor stimulation of AKT phosphorylation was inhibited after overexpression of ILK-DN (lanes 2 and 6, respectively). Competition of ILK-WT was observed with increasing concentrations of ILK-DN (the ratio of ILK-WT:ILK-DN is indicated above). Bottom, Immunoblots were stripped and subsequently reprobed with an anti-AKT antibody as a control for His-tagged, AKT fusion protein loading.

Biotechnology). The sections were incubated with a biotinylated antirabbit IgG followed by a streptavidin-horseradish peroxidase conjugate. The final reaction product was visualized with DAB. Controls included replacement of the primary antibody with normal rabbit IgG.

Cultured cells were fixed for $10 \mathrm{~min}$ in $3-4 \%$ paraformaldehyde in PBS, pH 7.4. Depending on the antigen, cells were solubilized in $0.02 \%$ or $0.1 \%$ Triton X-100 and blocked in PBS containing 5\% NGS and $1 \%$ BSA. Primary antibodies to ILK (1:400; StressGen Biotechnologies Corporation; 1:100, Upstate Biotechnology), or neurofilament (1:500, SigmaAldrich, Oakville, Ontario, Canada) were incubated for $1 \mathrm{hr}$ at $37^{\circ} \mathrm{C}$ or overnight at $4^{\circ} \mathrm{C}$. Protein was detected after incubation at $37^{\circ} \mathrm{C}$ with anti-rabbit rhodamine-conjugated (Santa Cruz Biotechnology) or Cy3conjugated (Jackson ImmunoResearch, Mississauga, Ontario, Canada) secondary antibodies. For double-labeling studies of mouse cerebellar granule cultures, a monoclonal antibody to ILK (Upstate Biotechnology) and rabbit polyclonal anti- $\beta 1$ antiserum (a kind gift from Dr. S. Carbonetto, McGill University) was incubated as stated above, and protein was detected after incubation with anti-rabbit rhodamine-conjugated (Santa Cruz Biotechnology) or anti-mouse fluorescein isothiocyanate-conjugated secondary antibodies (Santa Cruz Biotechnology). In the doublelabeling experiments, data were collected sequentially to prevent bleedthrough. Specificity of the immunofluorescence was established by comparing sister cultures incubated with the same concentration of rabbit IgG or secondary antibody alone.

\section{Results}

\section{Expression levels of ILK in rat and human tissue}

Messenger RNA levels of ILK are expressed in a wide variety of tissue, including the heart, kidney, and brain (Hannigan et al., 1996). Although ILK protein expression in various brain regions has not been studied, high ILK immunoreactivity in tumors with primitive neural differentiation has recently been demonstrated (Chung et al., 1998). Hybridization of a human multiple tissue expression array of poly $\left(\mathrm{A}^{+}\right)$selected RNA with an ILK cDNA probe indicate that ILK is expressed in a variety of brain regions (Fig. 1A). Furthermore, Western blot analysis indicate protein expression to be high in various brain regions relative to tissue known to express high ILK mRNA levels such as the heart. Areas of the brain expressing high ILK levels include the cortex, hippocampus, and cerebellum. Immunoblot analysis of homoge-
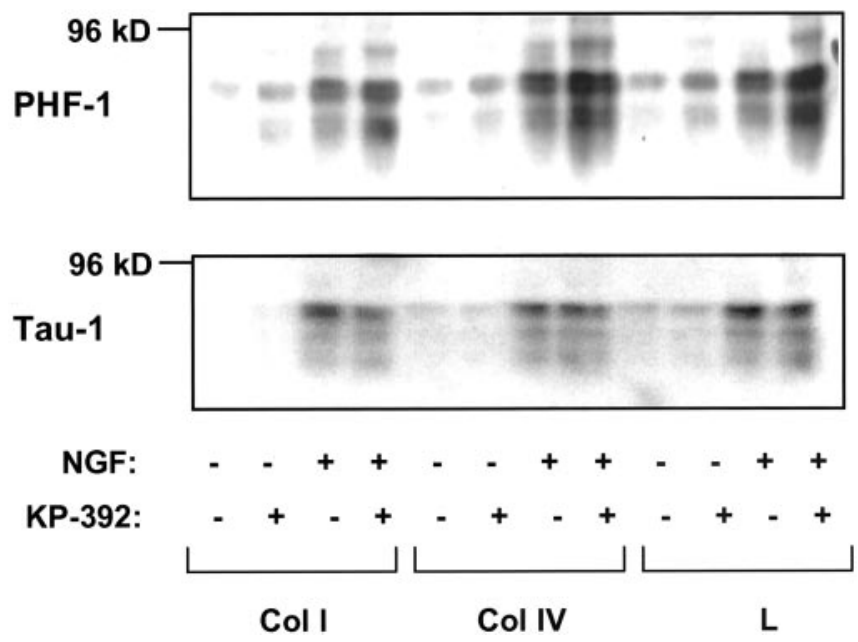

Figure 6. ILK inhibition increases Tau hyperphosphorylation in PC12 cells after integrin and NGF receptor stimulation. A representative Western blot of the effect of KP-392 (100 $\mu \mathrm{M})$ on levels of PHF-1 in PC12 cells grown on collagen I (Col I), collagen IV ( $C O / I V)$, or laminin ( $L$ ) after a $48 \mathrm{hr}$ incubation in media lacking serum with or without NGF $(50 \mathrm{ng} / \mathrm{ml}) ; n=3$. The bottom panel shows Tau-1-immunoreactive bands from the same blot as a control for protein expression levels.

nates taken from the fetal or adult human brain reveal that protein levels of ILK increase with age (Fig. 1C). This finding is consistent with the dot blot analysis because ILK mRNA levels were approximately four times higher in the adult human brain than in the fetal brain (16.4 and 4.8/100 ng of DNA, respectively).

\section{Immunocytochemical localization of ILK in neuronal cells}

Although Western blot analysis revealed high expression of ILK in the rat CNS, the cellular and subcellular distributions of ILK were unknown. To address these questions, human brain slices were stained for ILK. ILK-immunoreactive cells were detected within the same regions of the human brain that expressed ILK mRNA and ILK protein (Fig. 2). High magnification of human hippocampal and cerebellar coronal sections reveal intense ILK immunoreactivity in the neuronal cell bodies and dendrites of CA1 pyramidal cells and Purkinje cells, respectively. In contrast, the neuronal cell nucleus appeared devoid of ILK staining (Fig. 2).

Immunocytochemical localization of ILK in cultured cells plated on various ECM substrates was similar to the staining pattern observed in paraffin-embedded sections. In neuronal cells grown in vitro, ILK immunoreactivity was strong throughout the neuronal cell body and processes (Fig. 3). In differentiated PC12 cells overexpressing gp $140^{\text {trk }}$ and grown on collagencoated coverslips, ILK staining produced a granular pattern that was especially evident in the soma and neurite tip (Fig. 3A). PC12 cells overexpressing gp $140^{\text {trk }}$ were used simply for convenience because they differentiated more rapidly. A similar staining pattern for ILK was observed for wild-type PC12 cells cultured alone or in the presence of NGF (J. Mills and S. Dedhar, unpublished observations). At the growth cones of DRG neurons, ILK staining was punctate and uniformly distributed and extended to the periphery of growth cones into the tips of filopodia (Fig. $3 E$ ). The fine punctate staining of ILK is reminiscent of point contacts (Arregui et al., 1994) and is consistent with a cytoskeletal associated protein. Indeed the colocalization of ILK with the $\beta 1$ integrin subunit in cerebellar granule neurons supports this hypothesis (Fig. $3 F-H$ ). In contrast, axonal staining of ILK in DRG neurons was more continuous and appeared to be cytoskeletal-associated 
A
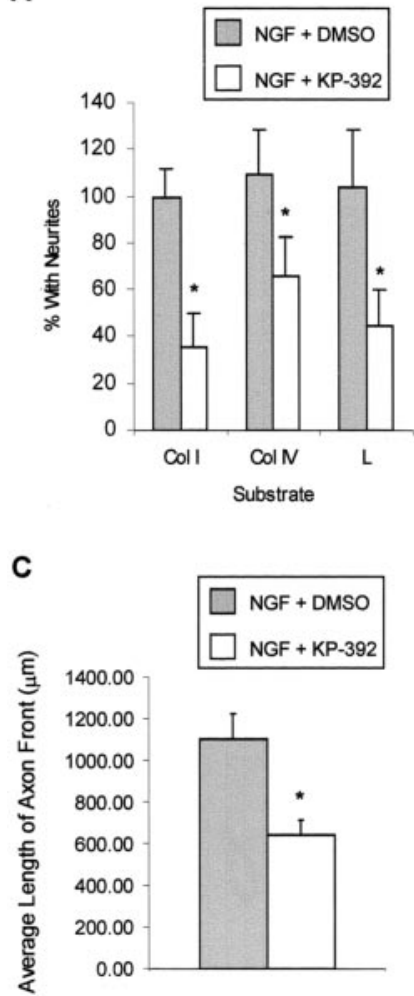

B

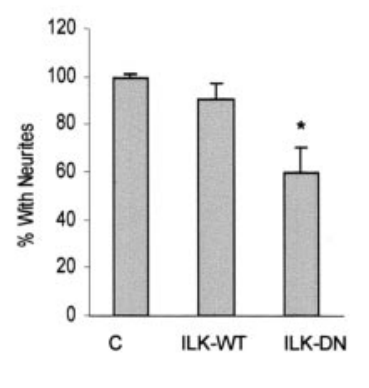

D

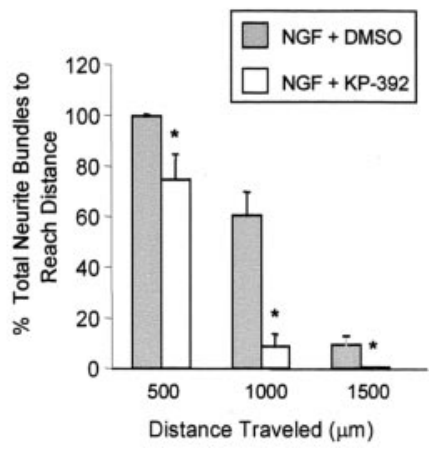

Figure 7. Inhibition of ILK attenuates NGF-induced neurite outgrowth in PC12 cells and DRG cells. A, NGF-induced neurite outgrowth was assessed in $\mathrm{PC} 12$ cells grown for $48 \mathrm{hr}$ on various ECM [collagen I (Col I), collagen IV (Col IV), or laminin ( $L$ )], in the presence or absence of KP-392 $(100 \mu \mathrm{m})$ or drug vehicle. The number of neurite-bearing PC12 cells after NGF treatment was significantly reduced in the presence of KP-392. Data represent four independent experiments \pm SEM and have been normalized to $P C 12$ cells grown on collagen I. ${ }^{*} p<0.05$, different from control cells plated onto the same extracellular matrix. $B$, NGF-induced neurite outgrowth was measured in PC12 cells plated onto collagen I and transiently cotransfected with ILK-WT, ILK-DN, or empty vector together with EGFP. The percentage of neurite-bearing cells was determined from cells positive for EGFP expression. Data represent four independent experiments \pm SEM. ${ }^{*} p<0.05$, different from control cells plated on collagen I. C, Average length of axon front cultured in the presence of KP-392 for $24 \mathrm{hr}$ was significantly decreased compared with the drug vehicle. $D$, Assessment of the total percentage of neurite bundles reaching a distance of 500,1000 , or $1500 \mu \mathrm{m}$ shows a significant decrease at each distance in the presence of KP-392. Data represent 18 explants from four independent experiments \pm SEM. ${ }^{*} p<0.05$, different from treatment groups lacking inhibitor grown on the same extracellular matrix.

(Fig. $3 C, D)$. This tubular staining pattern extended into the neuritic shaft and central regions of the growth cone (Fig. 3D).

\section{NGF-induced phosphorylation of AKT on serine- 473 is dependent on ILK activity}

In neuronal cell lines, integrin and NGF binding have been shown to result in activation of the PI-3 kinase-dependent-AKT signaling pathway (Andjelkovic et al., 1998; Ashcroft et al., 1999; Sarner et al., 2000). To determine whether NGF stimulates ILK and leads to AKT signaling, PC12 cells were stimulated with NGF, and ILK activity was measured using AKT as a substrate. Using a sensitive radioactive in vitro kinase assay, we found that ILK activation in PC12 cells plated onto laminin was maximal at $20 \mathrm{ng} / \mathrm{ml} \mathrm{NGF}$ (Fig. 4A). Similarly, using an alternate approach (Digicaylioglu and Lipton, 2001) ILK activity in PC12 cells plated onto collagen I was found to increase after a 10 min exposure to NGF (Fig. $4 B$ ). To determine the importance of ILK in NGF-induced neuronal signaling, PC12 cells were plated onto various ECM and stimu-

lated with NGF in the presence of KP-392, a pharmacological inhibitor of ILK or after transient transfection of ILK-DN. KP-392 has previously been shown to be a highly selective ILK inhibitor, reducing phosphorylation of AKT on Ser-473 in a dose-dependent manner while having no effect on phosphoinositide-dependent kinase-1 (PDK-1), a kinase that regulates AKT by Thr-308 phosphorylation (Persad et al., 2000, 2001a,b; Troussard et al., 2000; Tan et al., 2001). Also, this small molecule inhibitor has been shown to be selective for ILK compared with a number of other purified protein kinases in vitro (Persad et al., 2001a). The $\mathrm{IC}_{50}$ of KP-392 for ILK is $\sim 0.3 \mu \mathrm{M}$ compared with $25 \mu \mathrm{M}$ or higher for the other kinases tested (Persad et al., 2001a). A higher concentration of the inhibitor is required when used on whole cells, probably because of poor cell permeability, but the selectivity of the inhibitor for ILK should be maintained in vivo. Phosphorylation of ERK and p38 MAPK in PC12 cells was not inhibited by KP-392 at concentrations that resulted in decreased GSK-3 and AKT phosphorylation (Fig. 4C,E). As has been shown for nonneuronal cells, Western blot analysis of PC12 cell lysates probed with phosphospecific antibodies for AKT and GSK-3 indicate that ILK is upstream from AKT and GSK-3 in PC12 cells. PC12 cells, plated onto collagen I were stimulated with NGF for $4 \mathrm{hr}$ in the presence of vehicle control or increasing concentrations of KP-392. NGF-induced stimulation of both AKT and GSK-3 phosphorylation was inhibited by KP-392 in a concentrationdependent manner (Fig. 4C). These observations suggest ILK resides downstream from a Trk receptor-mediated signaling pathway and that ILK regulates both AKT and GSK-3 in neuronal cell lines. Lysates run in parallel were also probed for phosphop38 MAPK because a recent study indicated that p38 MAPK was involved in ILK-mediated signal transduction and neurite outgrowth in N1E-115 cells deprived of serum (Ishii et al., 2001). Exposure of PC12 cells to NGF for $4 \mathrm{hr}$ induced a marked reduction in p38 MAPK phosphorylation. A comparatively small decrease in $\mathrm{p} 38$ MAPK phosphorylation was evident at the highest concentration of KP-392. This suggests that although p38 MAPK may be involved in ILK-mediated signal transduction in the absence of trophic support, in the presence of trophic factors, p38 MAPK may play a lesser role. Evidence that KP-392 is a specific inhibitor of ILK was obtained by analyzing the phosphorylation levels of other proteins known to be important in Trk receptor-dependent signaling. A $100 \mu \mathrm{M}$ concentration of KP-392 did not reduce tyrosine phosphorylation levels of the p 85 regulatory subunit of PI-3 kinase and TrkA $\left(\mathrm{Tyr}^{490}\right)$ when exposed to PC12 cells for $4 \mathrm{hr}$ in the presence of NGF (Fig. 4D). The effects of KP-392 on NGF-induced phosphorylation of AKT and GSK-3 were maintained during longterm exposure. PC12 cells plated onto various ECM substrates were stimulated with NGF for $48 \mathrm{hr}$ in the presence or absence of KP-392 $(100 \mu \mathrm{M})$. Western blot analysis indicate that the effects of KP-392 on AKT and GSK-3 phosphorylation were maintained during this time course (Fig. 4E). Lysates run in parallel were also immunoblotted with phosphospecific ERK 1 and 2 antibodies, because sustained ERK phosphorylation has been associated with Trk receptor stimulation in PC12 cells (Qui and Green, 1992). Further evidence for the specificity of KP-392 as an inhibitor of the PI-3 kinase-dependent AKT signaling pathway is indicated by the observation that ERK phosphorylation was not suppressed by ILK inhibition (Fig. 4E). The modest increase in ERK phosphorylation in the presence KP-392 was not consistently found between trials $(n=3)$. Transient overexpression of ILK-DN in PC12 cells also reduced NGFstimulated cell signaling. PC12 cells were transfected with ILK$\mathrm{DN}: \mathrm{V}_{5} 24 \mathrm{hr}$ before plating onto collagen I. Exposure of PC12 cells to NGF for 15 min increased AKT and GSK phosphorylation, 
and this effect was significantly reduced when ILK-DN was transiently overexpressed (Fig. $4 F$ ).

To determine whether growth factors stimulated ILK activity in primary neurons, in vitro kinase assays were performed on rat cerebrocortical cultures using AKT as a substrate and analyzing phosphorylation at Ser-473 (Fig. 5). A 15 min exposure to NGF (20 ng/ml) stimulated ILK activity. NGF stimulation of ILK activity was blocked in cultures transfected with the ILK-DN. Similarly, a concentration-dependent reduction of kinase activity after ILK-WT transfection and ILK-DN was observed with increasing amounts of ILK-DN plasmid.

\section{ILK inhibition increases}

\section{tau hyperphosphorylation}

GSK-3, a kinase highly expressed in the CNS (Takahashi et al., 1994) directly phosphorylates the microtubule-associated protein Tau, a protein involved in microtubule stability and maintenance of neuronal processes. Activation of GSK-3 (as a result of decreased phosphorylation) leads to Tau hyperphosphorylation, which in turn reduces both Tau binding to microtubules (Hong and Lee, 1997) and axon stability (Sayas et al., 1999). These phosphorylated forms of Tau can be recognized by monoclonal antibodies raised against the "Alzheimer's-like" state of Tau such as the phosphorylation-dependent antibody PHF-1 (serines 396/404). NGF has previously been shown to increase Tau protein expression in PC12 cells (Sado et al., 1995). Indeed, we found that both total Tau (Tau-1 immunoreactivity) and hyperphosphorylated Tau (PHF-1 immunoreactivity) increased concurrently in PC12 cells exposed to NGF compared with media alone, a finding consistent with this previous report (Fig. 6). However, only PHF-1 immunoreactivity was higher in KP-392-treated cultures in the presence of NGF, suggesting that this increase was attributable to increased phosphorylation of Tau. Densitometric analysis of PHF-1 Western blots indicate that KP-392 increased Tau hyperphosphorylation in the presence of NGF: KP-392 increased PHF-1 in cells plated onto collagen I, collagen IV, and laminin by $1.8,1.7$, and $1.8 \pm 0.28$, 0.27 , and 0.54 SEM, respectively $(n=3-5)$ (values expressed as fold above NGF alone). The observation that KP-392 increased hyperphosphorylation of Tau is consistent with the effect of KP392 on the phosphorylation state of the Tau kinase GSK-3. Hyperphosphorylation of Tau is decreased in the execution phase of apoptosis (Mills et al., 1998). Therefore the finding that KP-392 increases Tau hyperphosphorylation suggests that ILK inhibition does not affect PC12 cell survival and was consistent with more direct measurements of neuronal cell viability (see Fig. 9)

\section{ILK inhibition decreases NGF-induced neurite outgrowth in PC12 cells and DRG neurons plated onto various ECM}

The precise role of a PI-3 kinase-AKT-dependent pathway in mediating NGF-induced differentiation is controversial. However, several reports suggest that although PI-3 kinase activity may not be sufficient, it is necessary for the initiation of process formation (Kimura et al., 1994; Jackson et al., 1996; Kobayashi et al., 1997; Ashcroft et al., 1999). Because ILK appears to be an important effector in this signaling pathway, we examined whether ILK was necessary for neurite outgrowth. Therefore, we measured NGF-induced neurite outgrowth in PC12 cells and DRG neurons with or without KP-392 to determine the importance of ILK in neurotrophin-induced process formation. Neurite formation in PC12 cells grown on collagen I, collagen IV, and laminin was significantly reduced in the presence of KP-392 (Fig. $7 A$ ) (results were normalized to growth on collagen I). Similarly, transient expression of ILK-DN in PC12 cells significantly inhibited NGF-induced neurite formation compared with control cells expressing the empty vector (Fig. 7B). Axonal outgrowth of DRG neurons grown on laminin in the presence of $20 \mathrm{ng} / \mathrm{ml} \mathrm{NGF}$ was significantly reduced in the presence of $100 \mu \mathrm{M} \mathrm{KP}-392$ compared with vehicle control. Both the average axon length and the number of cells having neurites $>500,1000$, or $1500 \mu \mathrm{m}$ (Figs. $7 C, D, 8)$ was significantly reduced in DRG neurons exposed to KP-392.

\section{ILK inhibition does not reduce neuronal cell survival}

Inhibition of ILK has been shown to induce apoptosis by reducing AKT activity and by stimulating caspase activity in nonneuronal cells (Attwell et al., 2000). Therefore, to ensure that KP-392 was not inhibiting neurite outgrowth by adversely affecting survival, we measured survival by either TUNEL labeling or 

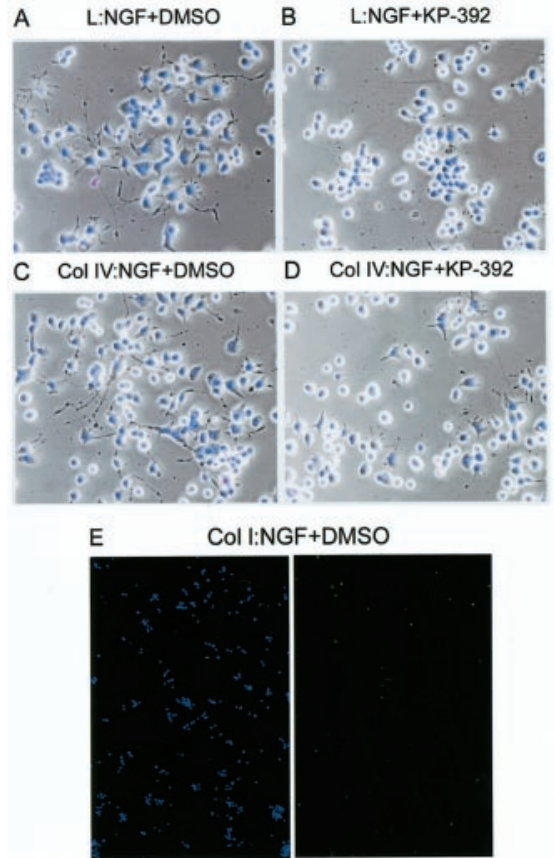

F

Col l:NGF+KP-392
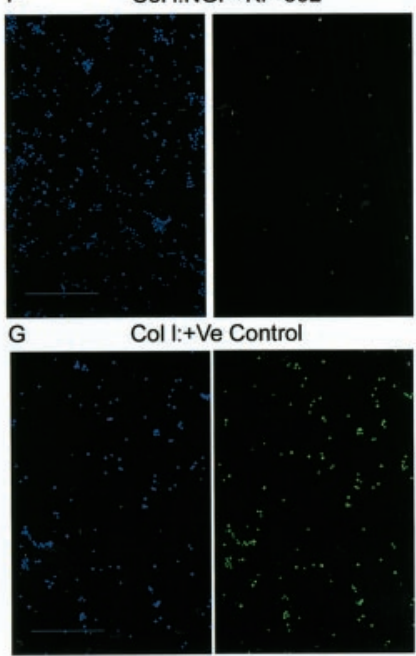

$\mathrm{H}$
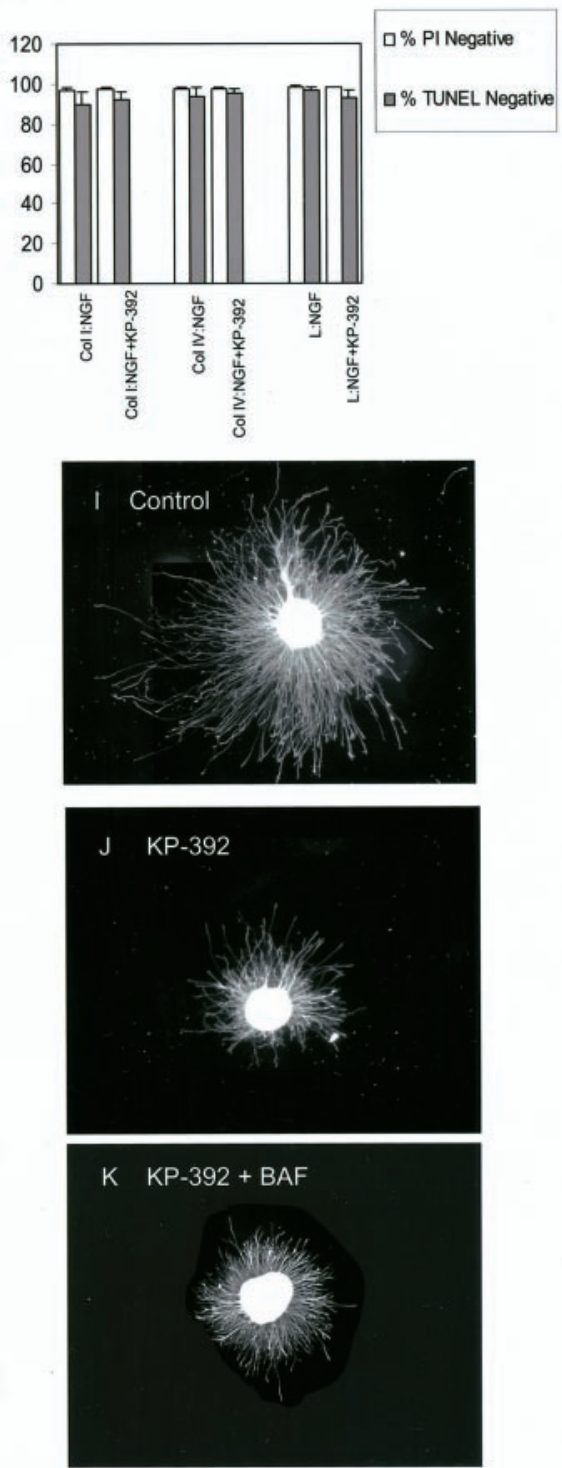

Figure 9. Inhibition of ILK does not decrease neuronal cell survival in the presence of NGF. $A-D$, Phase-contrast and fluorescence photomicrographs of $\mathrm{PC} 12$ cells plated onto laminin $(A, B)$ or collagen IV $(C, D)$ and exposed to NGF with or without KP-392. After 2 d, cells were fixed and stained with propidium iodide and Hoechst 33342. Inhibition of neurite outgrowth by KP-392 was independent from propidium iodide staining. $E-G$, Representative fluorescence photomicrographs of PC12 cells plated onto collagen I and exposed to NGF with or without KP-392. After 2 d cells were labeled for TUNEL (right). DAPI staining corresponding to each of these fields is shown in the adjacent left panel. A positive control, performed according the manufacturer's instructions (In Situ Cell Death Detection Kit; Boehringer Mannheim) is included (G). H, To assess survival, the number of propidium iodidenegative cells or TUNEL-negative cells was determined and expressed as a percentage of total cell number (Hoechst-positive or DAPI-positive cells, respectively); $n=3 \pm$ SD. I-K, Caspase inhibition did not block KP-392 effects on DRG neurite outgrowth. DRG neurons with neurofilament-labeled neurites after $24 \mathrm{hr}$ in the presence of NGF alone (I), with KP-392 (J), or KP-392 combined with the caspase inhibitor $\operatorname{BAF}(K)$.

staining with the DNA dye propidium iodide and counting nonapoptotic nuclei (Fig. 9). The percentage of either propidium iodide-negative or TUNEL-negative PC12 cells plated onto collagen or laminin was not reduced by a $48 \mathrm{hr}$ exposure to KP-392 (Fig. 9A-H). Moreover, KP-392-induced suppression of neurite outgrowth occurred in viable (propidium-negative) PC12 cells (Fig. 9A-D). Finally, in DRG neurons, KP-392-induced suppression of neurite outgrowth was not rescued by the caspase inhibitor BAF (Fig. 9I-K). Exposure of DRG neurons to NGF together with BAF appeared to increase the total number of neurites above control (data not shown). Taken together, these results suggest that KP-392-induced suppression of neurite outgrowth is not occurring as a result of compromised cell viability.

\section{Discussion}

Our study is the first to examine a role for ILK in neurons. We provide novel information on the expression pattern of ILK in the rodent and human brain and show that ILK colocalizes with the $\beta 1$ integrin subunit in neuronal cell bodies and processes. Moreover, we have examined a role for ILK in neuronal cell signaling and find that ILK regulates AKT during neurite growth promotion by NGF. We show that phospho-inhibition of the Tau kinase GSK-3, a physiological target of AKT and ILK, is also reduced by ILK inhibition leading to Tau hyperphosphorylation. These findings provide new insight into how growth factors may bring about cytoskeletal changes necessary for differentiation and suggest that ILK is an important effector in NGF-mediated neurite outgrowth.

Trophic effects of growth factors such as NGF are mediated by recruitment and activation of PI-3 kinase at the plasma membrane (Kaplan and Miller, 1997, 2000). PI-3 kinase activity promotes the production of the second messengers $\mathrm{PI}(3$, $4,5) \mathrm{P}_{3}$ and $\mathrm{PI}(3,4) \mathrm{P}_{2}$. High-affinity association of these second messengers with AKT allows for its translocation to the membrane and subsequent activation (Andjelkovic et al., 1997). In non-neuronal cells, activation of AKT is regulated via phosphorylation at two sites, Thr-308 and Ser-473, by PDK-1 (Downward, 1998; Datta et al., 1999) and ILK (Delcommenne et al., 1998; Attwell et al., 2000; Persad et al., 2000), respectively. Despite the potential importance of ILK and PDK-1 in regulating AKT, the role of these kinases in neuronal AKT-dependent pathways has not been characterized. Using Western blot analysis we show that ILK regulates $\mathrm{AKT}$ phosphorylation after NGF stimulation of PC12 cells grown on collagen and laminin. Furthermore, we show that ILK kinase activity is stimulated by this neurotrophin in primary neurons. Our findings indicate that ILK is an important regulator of growth factor-mediated signaling in neurons and present ILK as a potential effector, linking PI-3 kinase activation and AKT regulation. Our observation extends the role of ILK in growth factor signaling to include members of the neurotrophin family.

During neurite outgrowth, soluble or substrate-bound cues must be translated into cytoskeletal rearrangements (Gallo and Letourneau, 1999, 2000). One way extracellular cues can regulate these cytoskeletal changes is through signaling pathways that phosphorylate proteins involved in axonal stability, such as Tau. 


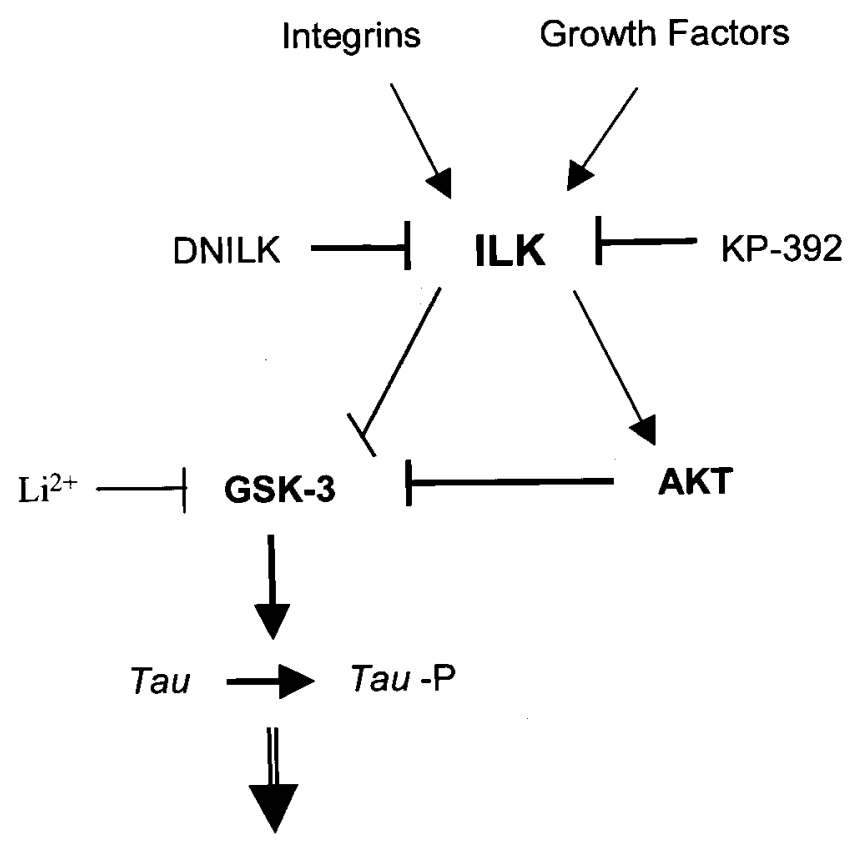

\section{Microtubule instability and inhibition of neurite outgrowth}

Figure 10. Schematic model of integrin and NGF-mediated ILK regulation of differentiation. ILK activity is regulated by integrins and growth factors in a PI-3 kinase-dependent manner. Active ILK phosphorylates AKT on Ser-473, resulting in its activation. Activated AKT in turn phosphorylates and inhibits GSK-3. ILK may also inhibit GSK-3 activity directly. Inhibition of ILK by KP-392 would thus increase GSK-3 activity and result in Tau hyperphosphorylation, microtubule instability, and decreased neurite growth.

The Tau kinase GSK-3 is negatively regulated by AKT through phospho-inhibition. Inhibition of GSK activity is thought to be important during neuronal differentiation (Garcia-Perez et al., 1999; Hall et al., 2000) and prevents axonal instability by preventing hyperphosphorylation of the microtubule-associated protein Tau. Tau hyperphosphorylation has previously been shown to decrease the association of Tau with microtubules (Hong and Lee, 1997) and inhibit total neurite number (Cressman and Shea, 1995; Malchiodi-Albedi et al., 1997; Sayas et al., 1999). Our study has demonstrated that ILK also modulates GSK-3 activity in neuronal cells. We show that the ILK inhibitor KP-392 decreased both NGF and integrin receptor-mediated phospho-inhibition of GSK-3. This suggests that, as in non-neuronal cells, ILK activation results in phospho-inhibition of GSK-3 either directly (Delcommenne et al., 1998; Troussard et al., 1999) or indirectly via AKT (Cross et al., 1995). Downregulation of GSK-3 by ILK was further suggested by the finding that ILK inhibition coincidentally promoted hyperphosphorylation of the GSK-3 substrate $\mathrm{Tau}$. Furthermore, ILK inhibition was shown to reduce neurite outgrowth in both PC12 cells and DRG neurons. Therefore, we propose that integrin and growth factor-mediated signaling upregulates ILK and AKT activity, which in turn downregulates GSK-3 activity and Tau hyperphosphorylation. This model supports a role for ILK in promoting increased stabilization of axonal structures during neurite outgrowth (Fig. 10).

NGF is involved in multiple cellular processes, including differentiation and cell survival. A role for PI-3 kinase/AKT signaling in NGF-induced neurite outgrowth and anti-apoptotic effects of NGF has been found (Kimura et al., 1994; Yao and Cooper, 1995; Jackson et al., 1996; Kobayashi et al., 1997; Ashcroft et al.,
1999). In the present study, although ILK inhibition decreased AKT activity and phosphoinhibition of GSK-3, suppression of neurite outgrowth did not appear to occur as a result of compromised cell viability (Fig. 9). This finding is somewhat surprising given the fact that AKT and GSK-3 have been identified as key effectors of an NGF-induced PI-3 kinase survival pathway (Yao and Cooper, 1995; Pap and Cooper, 1998). One difference between these studies and ours is the presence of extracellular matrix adhesion during long-term exposure to NGF. This may be an important distinction because integrin engagement results in activation of a PI-3 kinase-AKT survival pathway in neuronal cells (Gary and Mattson, 2001). Given that NGF and integrins both activate this signaling pathway it is likely that neuronal resistance to apoptosis induced by AKT inhibition is higher in the presence of these two survival signals. Similarly, comparisons between our studies and previous studies are confounded by the fact that PI-3 kinase inhibitors or mutant receptors that fail to activate PI-3 kinase inhibit other phosphoinositide-dependent kinases in addition to ILK (Toker and Newton, 2000).

To date, studies on the role of ILK have primarily emphasized the contribution of ILK to oncogenic transformation, a process that is tightly linked with its cell survival functions. For example, overexpression of ILK in epithelial cell suppresses anoikis and promotes anchorage-independent growth and tumorigenicity in vivo (Dedhar, 2000). Some of these changes are likely the result of the activation of AKT by ILK, an effect known to inhibit apoptosis. Indeed, in a number of human malignancies there is a loss in the expression or activity of the tumor suppressor PTEN (phosphatase and tensin homolog deleted on chromosome 10), a protein phosphatase responsible for the conversion of $\mathrm{PI}(3,4,5) \mathrm{P}_{3}$ to $\mathrm{PI}(4,5) \mathrm{P}_{2}$. Because ILK is dependent on $\mathrm{PI}(3,4,5) \mathrm{P}_{3}$ for its full activation, absence of PTEN results in constitutively activated ILK and AKT (Persad et al., 2001b). Elevated basal ILK and AKT activity may make this malignant cell model more vulnerable to KP-392-induced apoptosis. The role of ILK in survival functions may also be dependent on trophic factors because inhibition of ILK activity has been shown to increase apoptosis in the absence of trophic support (Attwell et al., 2000). More recently, the role of ILK in differentiation and motility have begun to be explored. For example, ILK has been shown to have a role in myogenic differentiation and $\mathrm{Ca}^{2+}$-independent smooth muscle contraction (Huang et al., 2000; Deng et al., 2001). In the neuronal cell line N1E-115, p38 MAPK appears to be involved in ILK-mediated signal transduction and differentiation in the absence of trophic support, whereas our study indicates that p38 MAPK plays a lesser role in the presence of trophic factors such as NGF. The neuroprotective properties of NGF may also explain why ILK inhibition, in our study, did not appear to decrease neuronal cell survival. Clearly involvement of ILK in these multifactorial cell processes is both context- and cell type-specific.

Integrins, a major class of ECM receptors, often partner with growth factors to integrate soluble and substrate-bound cues for maximal neurite outgrowth. Mechanisms that underlie this coordinated action in neurite outgrowth have only recently been addressed. For example, it has been shown that NGF increases the expression of integrins (Zhang et al., 1993) that accumulate as dense aggregates at the tips of filopodia (Grabham and Goldberg, 1997), thereby potentially altering integrin-cytoskeletal interactions at neuronal growth cones. Although it has been shown that both integrins and growth factors stimulate PI-3 kinasedependent differentiation pathways, the level of interdependence of these extracellular cues is unknown. Because ILK appears to regulate the microtubule-associated protein Tau and link inte- 
grins to the actin cytoskeleton, ILK may be an important effector, regulating various cytoskeletal rearrangements necessary for integrin and/or growth factor-mediated neurite outgrowth.

\section{References}

Andjelkovic M, Alessi DR, Meier R, Fernandez A, Lamb NJ, Frech M, Cron M, Cohen P, Lucocq JM, Hemmings BA (1997) Role of translocation in the activation and function of protein kinase B. J Biol Chem 272:31515-31524.

Andjelkovic M, Suidan HS, Meier R, Frech M, Alessi DR, Hemmings BA (1998) Nerve growth factor promotes activation of the $\alpha, \beta$ and $\gamma$ isoforms of protein kinase B in PC12 pheochromocytoma cells. Eur J Biochem 251:195-200.

Arregui CO, Carbonetto S, McKerracher L (1994) Characterization of neural cell adhesion sites: point contacts are the sites of interaction between integrins and the cytoskeleton in PC12 cells. J Neurosci 14:6967-6977.

Ashcroft M, Stephens RM, Hallberg B, Downward J, Kaplan DR (1999) The selective and inducible activation of endogenous PI 3-kinase in PC12 cells results in efficient NGF-mediated survival but defective neurite outgrowth. Oncogene 18:4586-4597.

Attwell S, Roskelley C, Dedhar S (2000) The integrin-linked kinase (ILK) suppresses anoikis. Oncogene 19:3811-3815.

Bonfoco E, Krainc D, Ankarcrona M, Nicotera P, Lipton SA (1995) Apoptosis and necrosis: two distinct events induced, respectively, by mild and intense insults with $N$-methyl-D-aspartate or nitric oxide/superoxide in cortical cell cultures. Proc Natl Acad Sci USA 92:7162-7166.

Chung DH, Lee JI, Kook MC, Kim JR, Kim SH, Choi EY, Park SH, Song HG (1998) ILK ( $\beta 1$-integrin-linked protein kinase): a novel immunohistochemical marker for Ewing's sarcoma and primitive neuroectodermal tumour. Virchows Arch 433:113-117.

Cohen-Cory S, Dreyfus CF, Black IB (1991) NGF and excitatory neurotransmitters regulate survival and morphogenesis of cultured cerebellar Purkinje cells. J Neurosci 11:462-471.

Cressman CM, Shea TB (1995) Hyperphosphorylation of Tau and filopodial retraction following microinjection of protein kinase $\mathrm{C}$ catalytic subunits. J Neurosci Res 42:648-656.

Cross DAE, Alessi DR, Cohen P, Andjelkovich M, Hemmings BA (1995) Inhibition of glycogen synthase kinase- 3 by insulin mediated protein kinase B. Nature 378:785-789.

Datta SR, Brunet A, Greenberg ME (1999) Cellular survival: a play in three AKTs. Gene Dev 13:2905-2927.

Dedhar S (2000) Cell-substrate interactions and signalling through ILK. Curr Opin Cell Biol 12:250-256.

Dedhar S, Williams B, Hannigan G (1999) Integrin-linked kinase (ILK): a regulator of integrin and growth-factor signalling. Trends Cell Biol 9:319-323.

Delcommenne M, Tan C, Gray V, Rue L, Woodgett J, Dedhar S (1998) Phosphoinositide-3-OH kinase-dependent regulation of glycogen synthase kinase 3 and protein kinase B/AKT by the integrin-linked kinase. Proc Natl Acad Sci USA 95:11211-11216.

Deng JT, Lierop JEV, Sutherland C, Walsh P (2001) $\mathrm{Ca}^{2+}$-independent smooth muscle contraction. J Biol Chem 276:16365-16373.

Digicaylioglu M, Lipton SA (2001) The neuroprotective effect of erythropoietin involves cross-talk between the Jak2 and NF- $\kappa \mathrm{B}$ signalling cascades. Nature 412:641-647.

Downward J (1998) Mechanisms and consequences of activation of protein kinase B/AKT. Curr Opin Cell Biol 10:262-267.

Gallo G, Letourneau PC (1999) Axon guidance: a balance of signals sets axons on the right track. Curr Biol 9:R490-R492.

Gallo G, Letourneau PC (2000) Neurotrophins and the dynamic regulation of the neuronal cytoskeleton. J Neurobiol 44:159-173.

Garcia-Perez J, Avila J, Diaz-Nido J (1999) Lithium induces morphological differentiation of mouse neuroblastoma cells. J Neurosci Res 15:261-270.

Gary DS, Mattson MP (2001) Integrin signalling via the PI 3-kinase-AKT pathway increases neuronal resistance to glutamate-induced apoptosis. J Neurochem 76:1485-1496.

Grabham PW, Goldberg DJ (1997) Nerve growth factor stimulates the accumulation of $\beta 1$ integrin at the tips of filopodia in the growth cones of sympathetic neurons. J Neurosci 17:5455-5465.

Hall AC, Lucas FR, Salinas PC (2000) Axonal remodelling and synaptic differentiation in the cerebellum is regulated by WNT-7a signaling. Cell 100:525-535.
Hannigan GE, Leung-Hagesteijn C, Fitz-Gibbon L, Coppolino M, Radeva G, Filmus J, Bell JC, Dedhar S (1996) Regulation of cell adhesion and anchorage-dependent growth by a new beta 1-integrin-linked protein kinase. Nature 379:91-96.

Hempstead BL, Rabin SJ, Kaplan L, Reid S, Parada LF, Kaplan DR (1992) Overexpression of the trk tyrosine kinase rapidly accelerates nerve growth factor-induced differentiation. Neuron 9:883-896.

Hong M, Lee VM-Y (1997) Insulin and insulin-like growth factor-1 regulate tau phosphorylation in cultured human neurons. J Biol Chem 272:19547-19553.

Huang Y, Li J, Zhang Y, Wu C (2000) The roles of integrin-linked kinase in the regulation of myogenic differentiation. J Cell Biol 150:861-872.

Ishii T, Satoh E, Nishimura M (2001) Integrin-linked kinase controls neurite outgrowth in N1E-115 neuroblastoma cells. J Biol Chem 276:42994-43003.

Jackson TR, Blader IJ, Hammonds-Odie LP, Burga CR, Cooke F, Hawkins PT, Wolf AG, Heldman KA, Theibert AB (1996) Initiation and maintenance of NGF-stimulated neurite outgrowth requires activation of a phosphoinositide 3-kinase. J Cell Sci 109:289-300.

Kaplan DR, Miller FD (1997) Signal transduction by the neurotrophin receptors. Curr Opin Cell Biol 9:213-221.

Kaplan DR, Miller FD (2000) Neurotrophin signal transduction in the nervous system. Curr Opin Cell Biol 10:381-391.

Kimura K, Hattori S, Kabuyama K, Shizawa Y, Takayanagi J, Nakamura S, Toki S, Matsuda Y, Onodera K, Fukui Y (1994) Neurite outgrowth of PC12 cells is suppressed by wortmannin, a specific inhibitor of phosphatidylinositol 3-kinase. J Biol Chem 269:18961-18967.

Kobayashi M, Nagata S, Kita Y, Nakatsu N, Ihara S, Kaibuchi K, Kuroda S, Ui M, Iba H, Konishi H, Kikkawa U, Saitoh I, Fukui Y (1997) Expression of a constitutively active phosphatidylinositol 3-kinase induces process formation in rat PC12 cells. J Biol Chem 272:16089-16092.

Li F, Zhang Y, Wu C (1999) Integrin-linked kinase is localized to cell-matrix focal adhesions but not cell-cell adhesion sites and the focal adhesion localization of integrin-linked kinase is regulated by the PINCH-binding ANK repeats. J Cell Sci 112:4589-4599.

Ling J, Liu Z, Wang D, Gladson CL (1999) Malignant astrocytoma cell attachment and migration to various matrix proteins is differentially sensitive to phosphoinositide 3-OH inhibitors. J Cell Biochem 73:533-544.

Malchiodi-Albedi F, Petrucci TC, Picconi B, Iosi F, Falchi M (1997) Protein phosphatase inhibitors induce modification of synapse structure and tau hyperphosphorylation in cultured rat hippocampal neurons. J Neurosci 48:425-438.

Miller TM, Moulder KL, Knudson CM, Creedon DJ, Deshmukh M, Korsmeyer SJ, Johnson Jr EM (1997) Bax deletion further orders the cell death pathway in cerebellar granule cells and suggests a caspaseindependent pathway to cell death. J Cell Biol 139:205-217.

Mills JC, Lee VM-Y, Pittman RN (1998) Activation of a PP2A-like phosphatase and dephosphorylation of $\tau$ protein characterize onset of the execution phase of apoptosis. J Cell Sci 111:625-636.

Nikolopoulos SN, Turner CE (2001) Integrin-linked kinase (ILK) binding to paxillin LD1 motif regulates ILK localization to focal adhesions. J Cell Biol 276:23499-23505.

Pap M, Cooper GM (1998) Role of glycogen synthase kinase-3 in the phosphatidylinositol 3-kinase/AKT cell survival pathway. J Biol Chem 273:19929-19932.

Persad S, Attwell S, Gray V, Delcommenne M, Troussard A, Sanghera J, Dedhar S (2000) Inhibition of integrin-linked kinase (ILK) suppresses activation of protein kinase B/AKT and induces cell cycle arrest and apoptosis of PTEN-mutant prostate cancer cells. Proc Natl Acad Sci USA 97:3207-3212.

Persad S, Attwell S, Gray V, Mawji N, Deng JT, Leung D, Yan J, Sanghera J, Walsh MP, Dedhar S (2001a) Regulation of protein kinase B/Aktserine- 473 phosphorylation by integrin linked kinase (ILK): critical roles for kinase activity and amino acids arginine-211 and serine-343. J Biol Chem 276:27462-27469.

Persad S, Troussard AA, McPhee TR, Mulholland DJ, Dedhar S (2001b) Tumor suppressor PTEN inhibits nuclear accumulation of $\beta$-catenin and $\mathrm{T}$ cell/lymphoid enhancer factor 1-mediated transcriptional activation. J Cell Biol 153:1161-1173.

Qui MS, Green SH (1992) PC12 cell neuronal differentiation is associated with prolonged p21ras activity and consequent prolonged ERK activity. Neuron 9:705-717.

Sado E, Barg J, Rasouly D, Lazarovici P, Ginzburg I (1995) Short- and 
long-term mechanisms of tau regulation in PC12 cells. J Cell Sci 108:2857-2864.

Sarner S, Kozma R, Ahmed S, Lim L (2000) Phosphatidylinositol 3-kinase, cdc42, and racl act downstream of ras in integrin-dependent neurite outgrowth in N1E-115 neuroblastoma cells. Mol Cell Biol 20:158-172.

Sayas CL, Moreno-Flores TM, Avila J, Wandosell F (1999) The neurite retraction induced by lysophosphatidic acid increases Alzheimer's diseaselike tau phosphorylation. J Biol Chem 274:37046-37052.

Takahashi M, Tomizawa K, Kato R, Sato K, Uchida T, Fujita SC, Imahori K (1994) Localization and developmental changes of tau protein kinase 1/glycogen synthase kinase-3 beta in rat brain. J Neurochem 63:245-255.

Tan C, Costello P, Sanghera J, Dominguez D, Baulida J, Garcia de Herreros A, Dedhar S (2001) Inhibition of integrin linked kinase (ILK) suppresses $\beta$-catenin-Lef/Tcf-dependent transcription and expression of the E-cadherin repressor, snail, in APC $-/-$ human colon carcinoma cells. Oncogene 20:133-140.

Teng KK, Greene LA (1994) Cell biology: a laboratory handbook.

Toker A, Newton AC (2000) Cellular signaling: pivoting around PDK-1. Cell 103:185-188.

Troussard AA, Tan C, Yoganathan N, Dedhar S (1999) Cell-extracellular matrix interactions stimulate the AP-1 transcription factor in an integrinlinked kinase- and glycogen synthase kinase 3-dependent manner. Mol Cell Biol 19:7420-7427.

Troussard AA, Costello P, Yoganathan TN, Kumagai S, Roskelley CD, Dedhar S (2000) The integrin linked kinase (ILK) induces an invasive phenotype via $\mathrm{AP}-1$ transcription factor-dependent upregulation of matrix metalloproteinase 9 (MMP-9). Oncogene 19:5444-5452.
Tu Y, Li F, Wu C (1998) Nck-2, a novel Src homology2/3-containing adaptor protein that interacts with the LIM-only protein PINCH and components of growth factor receptor kinase signalling pathways. Mol Biol Cell 9:3367-3382.

Tu Y, Li F, Goicoechea S, Wu C (1999) The LIM-only protein PINCH directly interacts with integrin-linked kinase and is recruited to integrinrich sites in spreading cells. Mol Cell Biol 19:2425-2434.

Tu Y, Huang Y, Zhang Y, Hua Y, Wu C (2001) A new focal adhesion protein that interacts with integrin-linked kinase and regulates cell adhesion spreading. J Cell Biol 153:585-598.

Wu C (1999) Integrin-linked kinase and PINCH: partners in regulation of cell-extracellular matrix interaction and signal transduction. J Cell Sci 112:4485-4489.

Wu C, Dedhar S (2001) Integrin-linked kinase (ILK) and its interactors: a new paradigm for the coupling of extracellular matrix to actin cytoskeleton and signaling complexes. J Cell Biol 155:505-510.

Yamaji S, Suzuki A, Sugiyama Y, Koide Y-I, Yoshida M, Kanamori H, Mohri $\mathrm{H}, \mathrm{Ohno}$ S, Ishigatsubo Y (2001) A novel integrin-linked kinase-binding protein, affixin, is involved in the early stage of cell-substrate interaction. J Cell Biol 153:1251-1264.

Yao R, Cooper GM (1995) Requirement for phosphatidylinositol-3 kinase in the prevention of apoptosis by nerve growth factor. Science 267:2003-2006.

Zhang Z, Tarone G, Turner DC (1993) Expression of integrin and $\alpha 1 \beta 1$ is regulated by nerve growth factor and dexamethasone in PC12 cells. Functional consequences for adhesion and neurite outgrowth. J Biol Chem 268:5557-5568. 